\title{
Revealing fosfomycin primary effect on Staphylococcus aureus transcriptome: modulation of cell envelope biosynthesis and phosphoenolpyruvate induced starvation
}

\author{
Marko Petek*1, Špela Baebler+1, Drago Kuzman², Ana Rotter1 , Zdravko Podlesek³, Kristina Gruden'1, Maja Ravnikar \\ and Uroš Urleb²
}

\begin{abstract}
Background: Staphylococcus aureus is a highly adaptable human pathogen and there is a constant search for effective antibiotics. Fosfomycin is a potent irreversible inhibitor of MurA, an enolpyruvyl transferase that uses phosphoenolpyruvate as substrate. The goal of this study was to identify the pathways and processes primarily affected by fosfomycin at the genome-wide transcriptome level to aid development of new drugs.

Results: S. aureus ATCC 29213 cells were treated with sub-MIC concentrations of fosfomycin and harvested at 10, 20 and 40 minutes after treatment. S. aureus GeneChip statistical data analysis was complemented by gene set enrichment analysis. A visualization tool for mapping gene expression data into biological pathways was developed in order to identify the metabolic processes affected by fosfomycin. We have shown that the number of significantly differentially expressed genes in treated cultures increased with time and with increasing fosfomycin concentration. The target pathway - peptidoglycan biosynthesis - was upregulated following fosfomycin treatment. Modulation of transport processes, cofactor biosynthesis, energy metabolism and nucleic acid biosynthesis was also observed.

Conclusions: Several pathways and genes downregulated by fosfomycin have been identified, in contrast to previously described cell wall active antibiotics, and was explained by starvation response induced by phosphoenolpyruvate accumulation. Transcriptomic profiling, in combination with meta-analysis, has been shown to be a valuable tool in determining bacterial response to a specific antibiotic.
\end{abstract}

\section{Background}

Staphylococcus aureus is a common human pathogen. It is known to be highly adaptable, as shown in the rapid development of resistance to most known antibiotics. Much research in the last decade has been devoted to discovering new broad-spectrum antibiotic agents. A large proportion of effective antibiotics act on the cell wall which has been taken as an adequate target in the development of new drugs. Most cell wall active antibiotics in clinical use, for example $\beta$-lactams and glycopeptides, act by inhibiting late steps of peptidoglycan synthesis on the

* Correspondence: marko.petek@nib.si

1 Department of Biotechnology and Systems Biology, National Institute of

Biology, Večna pot 111, Ljubljana, SI-1000, Slovenia

+ Contributed equally

Full list of author information is available at the end of the article outer side of the cell membrane. The enzymes that catalyze the intracellular part of the peptidoglycan synthesis pathway, muramyl peptide ligases (Mur enzymes), are also good candidates for antibiotic drug targeting, because human cells do not synthesize similar enzymes. Inhibition of these enzymes causes substantial impairment of bacterial cell wall biosynthesis which, at higher doses of inhibitor, leads to decreased cell growth and to cell lysis. However, only two antibiotic agents targeting Mur enzymes are in clinical use, fosfomycin and cycloserine. Fosfomycin is a potent irreversible inhibitor of MurA, an enolpyruvyl transferase that catalyses the condensation of uridine diphosphate- $\mathrm{N}$-acetylglucosamine with phosphoenolpyruvate (PEP) [1]. This reaction is the first step in the peptidoglycan biosynthesis pathway. 
Genome-scale expression profiling, using microarray technology, can be used to determine potential drug targets [2]. The Staphylococcus aureus microarray metadatabase (SAMMD, [3]) contains sets of differentially expressed genes, identified by published $S$. aureus expression profiling experiments. This database simplifies comparison of experimental data and provides a quick overview of published experiments for this bacterium.

Our goal is to develop a platform for transcriptional profiling of new Mur ligase inhibitors. As a reference, the transcription profile was determined for the well characterized inhibitor of MurA ligase, fosfomycin. We have focused on the pathways and processes primarily affected by fosfomycin. In contrast to other genome-wide profiling studies of pathogen responses to antimicrobial substances, we have studied the response to low concentrations of antimicrobial agent early after its addition. An innovative data analysis approach, complemented by newly devised visualization tools, pathway analysis and meta-analysis of similar experiments, enabled us to identify differentially expressed gene groups and pathways, and to conclude that the response of the bacterium to fosfomycin is not only time but also concentration dependent.

\section{Results and discussion}

The experiment was designed to enable detection of primary effects of fosfomycin treatment, as opposed to the cell death related effects observed after prolonged exposure to high drug concentrations. The longest time of exposure was chosen to be $40 \mathrm{~min}$, which is approximately one cell cycle. Two concentrations of fosfomycin were used, $1 \mu \mathrm{g} / \mathrm{ml}$ and $4 \mu \mathrm{g} / \mathrm{ml}$, which affected bacterial growth only slightly (results not shown). The samples were processed and the data obtained analyzed according to strict protocol as shown schematically in Figure 1.

\section{Time and concentration dependent effects of fosfomycin}

The profile of differentially expressed genes varied substantially with time following treatment with fosfomycin. After ten minutes, only a small proportion of genes were significantly differentially expressed (Figure 2). This first time point was too short to detect global changes at the level of gene expression. The reaction to fosfomycin became more evident after $20 \mathrm{~min}$ and $40 \mathrm{~min}$ of incubation. The greatest number of differentially expressed genes was found at $4 \mu \mathrm{g} / \mathrm{ml}$ fosfomycin concentration, after 40 min incubation (t40c4) (Figure 2 and Figure 3). Not surprisingly, at both concentrations, the later time points were more similar to one another than to the time point 10 min of incubation in terms of common differentially expressed genes (Figure 2).

The concentration dependence of the transcriptome response was also observed at the individual gene level.

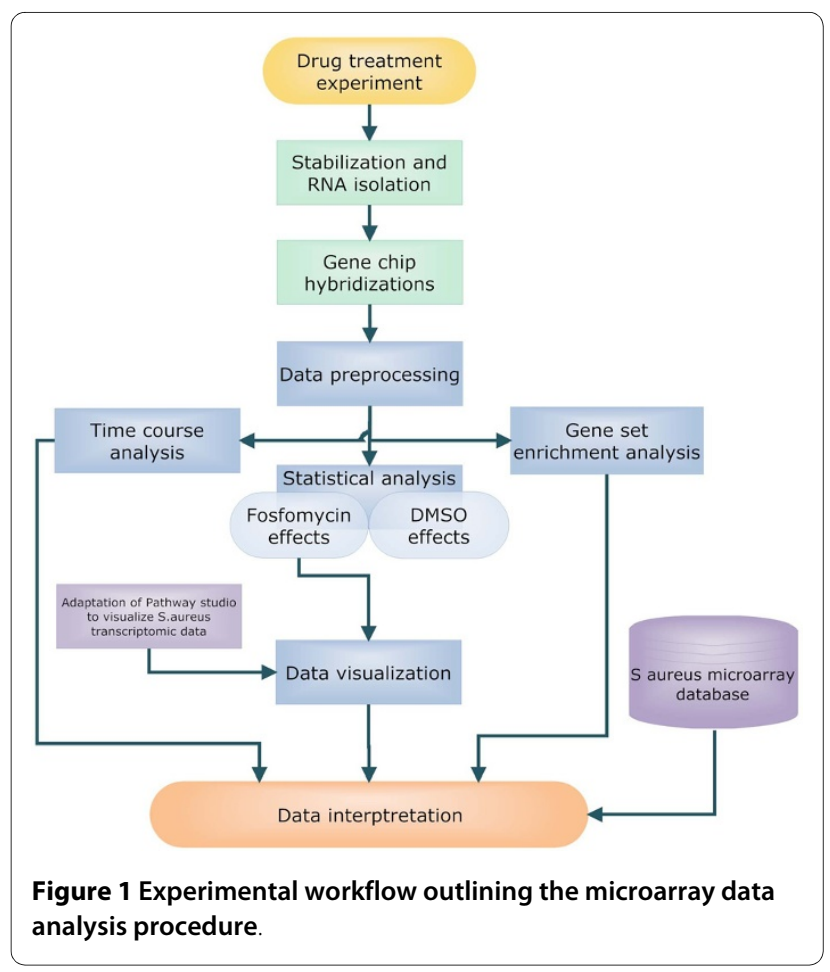

For example, alanine racemase gene SA1231, some transporter genes (opp2B, SA1183, SA1972, msmX, SA0207, malF) and amino acid biosynthesis genes $d h o M$ and his $C$ were significantly differentially expressed only at higher concentrations of fosfomycin (see Additional file 1).

\section{Metabolic pathways affected by fosfomycin treatment}

Analysis of gene groups and metabolic pathways is suitable for biological interpretation of microarray analysis results, where grouping is essential to retain the overview. We have chosen TIGRFAM functional classification to








group S. aureus genes by the known or predicted biochemical role of the protein they encode. The greatest proportion of differentially expressed genes belong to the groups "cell envelope", "transport and binding proteins" and "energy metabolism", indicating that these were the processes affected most by fosfomycin (Figure 3). A global transcriptional response became evident after 20 min of incubation. Interestingly, mainly the same processes were affected at both concentrations.

The results of pathway analysis obtained by the different approaches - one classifying differentially expressed genes (Figure 3), the other comparing the whole expression profiles by gene set enrichment analysis (GSEA) (Table 1) - were similar, confirming the biological significance of the results. Both approaches show that fosfomycin downregulated genes for amino acid biosynthesis, transport, and energy metabolism, but upregulated those for protein synthesis and protein fate (protein modification, trafficking, repair, and folding). Interestingly, GSEA shows that for cell envelope genes, purine and pyrimidine biosynthesis, and for regulatory genes, the switch in transcription regulation, occurred $20 \mathrm{~min}$ after treatment. The upregulation of genes for cell division after $40 \mathrm{~min}$ of treatment (Table 1) is important, since many components of this process are involved in cell envelope biosynthesis.
To strengthen the reliability of the microarray data, qPCR analysis was performed for five differentially expressed genes - two peptidoglycan biosynthesis genes, murZ and $s g t B$, autolysin gene $a t l$, cofactor biosynthesis gene $r i b B$ and oligopeptide transporter gene opp $B$ (Figure $4)$.

\section{Cell envelope synthesis is strongly affected by fosfomycin treatment}

The GSEA results showed that specific subgroups of genes in the cell envelope group were regulated differently (Table 1). Genes involved in murein and peptidoglycan biosynthesis, including teichoic acid biosynthesis genes, were upregulated, while surface polysaccharide metabolism genes were downregulated.

To interpret the changes in gene expression we visualized the data in Pathway Studio software. Since the peptidoglycan biosynthesis pathway is not complete in the existing metabolic network [4], the pathway was complemented with literature data. The .gpc file (Additional file 2) can be used by the scientific comunity to interpret gene expression data, enabling ready visual comparison of experimental results from different studies.

Fosfomycin caused weak upregulation of several mur genes (murIDZ, mraY) that encode enzymes involved in 
Table 1: Enriched gene sets after 10, 20 and 40 minutes of treatment with fosfomycin.

\begin{tabular}{|c|c|c|c|c|c|c|}
\hline \multirow[b]{2}{*}{ Gene set } & \multicolumn{3}{|c|}{ Downregulation } & \multicolumn{3}{|c|}{ Upregulation } \\
\hline & $10 \mathrm{~min}$ & $20 \mathrm{~min}$ & $40 \mathrm{~min}$ & $10 \mathrm{~min}$ & $20 \mathrm{~min}$ & $40 \mathrm{~min}$ \\
\hline AMINO ACID BIOSYNTHESIS_ASPARTATE FAMILY & 0.000 & 0.003 & 0.005 & & & \\
\hline AMINO ACID BIOSYNTHESIS_OTHER & & 0.171 & & & & \\
\hline $\begin{array}{l}\text { TRANSPORT AND BINDING PROTEINS_AMINO ACIDS, PEPTIDES AND } \\
\text { AMINES }\end{array}$ & & 0.000 & 0.010 & & & \\
\hline $\begin{array}{l}\text { TRANSPORT AND BINDING PROTEINS_CARBOHYDRATES, ORGANIC } \\
\text { ALCOHOLS, AND ACIDS }\end{array}$ & & 0.090 & 0.008 & & & \\
\hline $\begin{array}{l}\text { TRANSPORT AND BINDING PROTEINS_CATIONS AND IRON } \\
\text { CARRYING COMPOUNDS }\end{array}$ & & 0.078 & 0.228 & & & \\
\hline TRANSPORT AND BINDING PROTEINS_UNKNOWN SUBSTRATE & & 0.092 & 0.022 & & & \\
\hline ENERGY METABOLISM_AMINO ACIDS AND AMINES & & 0.135 & 0.008 & & & \\
\hline $\begin{array}{l}\text { ENERGY METABOLISM_ATP-PROTON MOTIVE FORCE } \\
\text { INTERCONVERSION, BIOSYNTHESIS AND DEGRADATION OF } \\
\text { POLYSACCHARIDES, PYRUVATE DEHYDROGENASE }\end{array}$ & & & 0.005 & & & \\
\hline ENERGY METABOLISM_GLYCOLYSIS_GLUCONEOGENESIS & & 0.088 & 0.238 & & & \\
\hline ENERGY METABOLISM_SUGARS AND TCA CYCLE & & 0.077 & 0.089 & & & \\
\hline SIGNAL TRANSDUCTION_PTS & & 0.033 & 0.008 & & & \\
\hline $\begin{array}{l}\text { CELL ENVELOPE_BIOSYNTHESIS AND DEGRADATION OF MUREIN } \\
\text { SACCULUS AND PEPTIDOGLYCAN }\end{array}$ & & & & & 0.068 & 0.015 \\
\hline $\begin{array}{l}\text { CELL ENVELOPE_BIOSYNTHESIS AND DEGRADATION OF SURFACE } \\
\text { POLYSACCHARIDES AND LIPOPOLYSACCHARIDES }\end{array}$ & & 0.000 & 0.009 & 0.228 & & \\
\hline CELL ENVELOPE_OTHER & & 0.087 & & & & \\
\hline CELLULAR PROCESSES_CELL DIVISION & & & & & 0.238 & 0.051 \\
\hline CELLULAR PROCESSES_PATHOGENESIS & & 0.237 & & & & \\
\hline CELLULAR PROCESSES_TOXIN PRODUCTION AND RESISTANCE & & & 0.068 & & & \\
\hline $\begin{array}{l}\text { CENTRAL INTERMEDIARY METABOLISM_NITROGEN METABOLISM } \\
\text { AND AMINO SUGARS }\end{array}$ & & & & & 0.046 & \\
\hline CENTRAL INTERMEDIARY METABOLISM_OTHER & & 0.140 & & & & \\
\hline PURINES, PYRIMIDINES, NUCLEOSIDES, AND NUCLEOTIDES & & 0.000 & & 0.036 & & \\
\hline REGULATORY FUNCTIONS_OTHER & & & & & & 0.169 \\
\hline PROTEIN SYNTHESIS_TRNA AMINOACYLATION & & 0.083 & & & & \\
\hline $\begin{array}{l}\text { PROTEIN FATE_DEGRADATION OF PROTEINS, PEPTIDES, AND } \\
\text { GLYCOPEPTIDES }\end{array}$ & & & & & 0.238 & 0.220 \\
\hline $\begin{array}{l}\text { PROTEIN FATE_PROTEIN AND PEPTIDE SECRETION AND } \\
\text { TRAFFICKING }\end{array}$ & & & & & 0.071 & 0.020 \\
\hline $\begin{array}{l}\text { PROTEIN FATE_PROTEIN MODIFICATION AND REPAIR_PROTEIN } \\
\text { FOLDING AND STABILIZATION }\end{array}$ & & & & & 0.132 & 0.000 \\
\hline $\begin{array}{l}\text { PROTEIN SYNTHESIS_RIBOSOMAL PROTEINS: SYNTHESIS AND } \\
\text { MODIFICATION_TRANSLATION FACTORS }\end{array}$ & & & & 0.001 & & 0.005 \\
\hline PROTEIN SYNTHESIS_TRNA AND RRNA BASE MODIFICATION & & & & & & 0.241 \\
\hline TRANSCRIPTION & & & & & & 0.030 \\
\hline DNA METABOLISM & & & & & & 0.249 \\
\hline
\end{tabular}

Downregulation corresponds to negative correlation and upregulation corresponds to positive correlation with the fosfomycin concentration. Numbers show false discovery rates (FDR). Only gene sets with FDR $<0.25$ in at least one time point are shown; bold is used when FDR $<0.05$. 


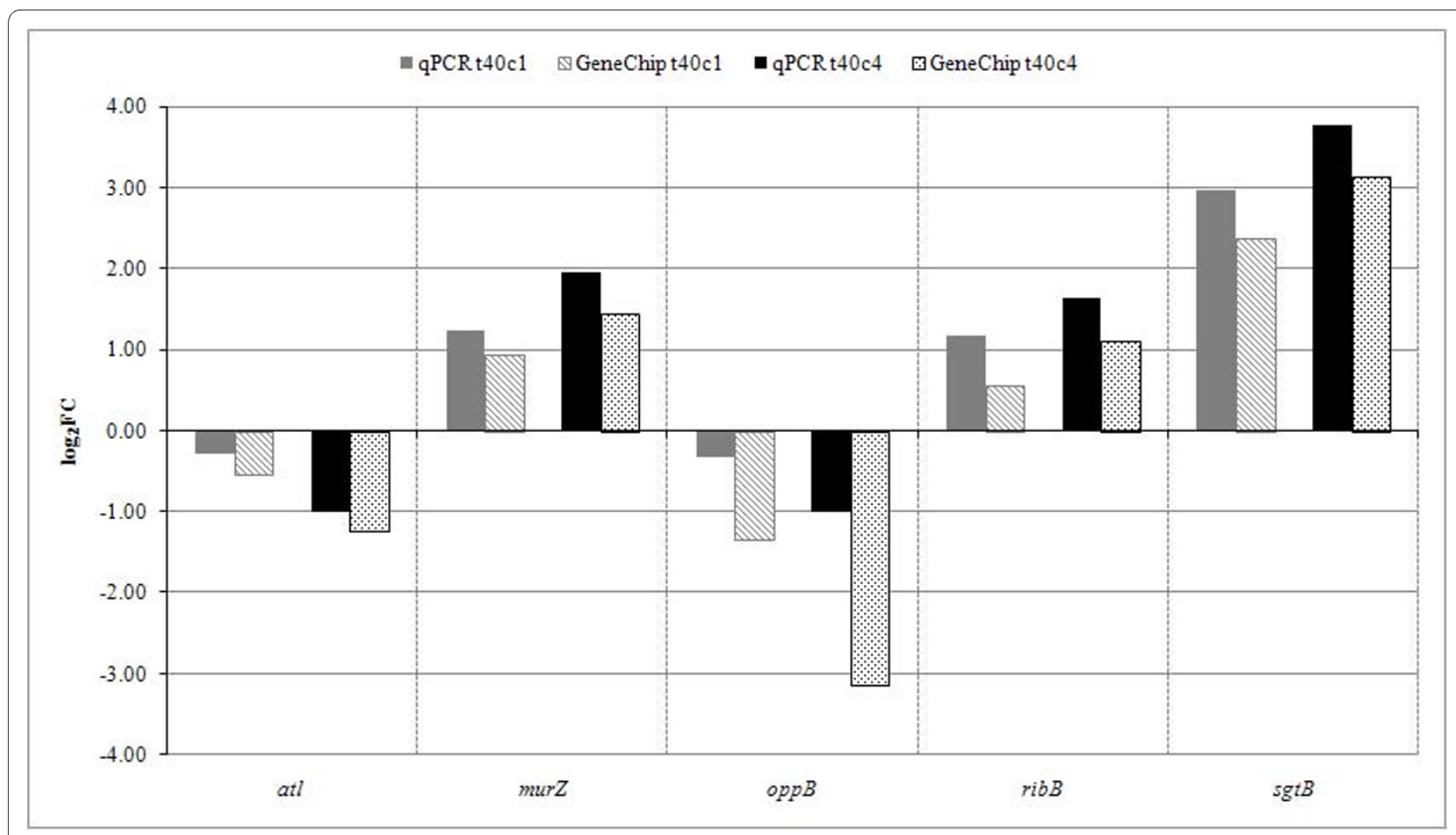

Figure 4 Verification of microarray results by qPCR. Differential expression of $a t l$, murZ, oppB, ribB, and sgtB genes was measured after 40 min of treatment with $1 \mu \mathrm{g} / \mathrm{ml}(\mathrm{t} 40 \mathrm{c} 1)$ and $4 \mu \mathrm{g} / \mathrm{ml}$ (t40c4) of fosfomycin. The histograms show $\log _{2}$ fold changes $\left(\log _{2} \mathrm{FC}\right)$. The filled bars show qPCR data and the patterned bars microarray data.

the first step of peptidoglycan biosynthesis (Figure 5). This was observed at time point t40c4 only. The most strongly induced of the mur genes was that encoding MurZ, a MurA homologue enzyme. Fosfomycin inhibits both MurA and MurZ, which are essential to Gram positive bacteria [5]. Nevertheless, the murA gene (with two probe sets on the chip: MurA, MurA_1; Figure 5) was not found to be significantly differentially expressed. Interestingly, some genes encoding enzymes acting in the final phases of peptidoglycan synthesis - pbpA, bacA, and sgtB - were more induced than the gene encoding the target enzyme (Figure 5). This suggests that inhibition of MurA and MurZ affects transcription of the whole metabolic pathway. In contrast to Escherichia coli, peptidoglycan biosynthetic genes in $S$. aureus are distributed evenly throughout the chromosome and are regulated independently. As shown by Sobral et al. [6], there is a striking complexity of transcription level links that connect a large number of diverse cellular functions to any particular step in cell wall synthesis.

Autolysin coding genes atl, lytH, SA0423, and SA2100 were downregulated at $\mathrm{t} 40 \mathrm{c} 4$, whereas lyt $M$ was upregulated by fosfomycin at that point (Figure 5) suggesting the prevention of further degradation of peptidoglycan. As well as in cell wall stress, gene atl has been found to be downregulated in acid shock [7], SOS response and, cold shock, but upregulated in stringent response [8].

A set of $S$. aureus genes responding to cell wall active antibiotics, termed the "cell wall stress stimulon", were first described by Utaida et al. [9]. They showed an orchestrated response following treatment with antibiotics acting at different stages of cell wall biosynthesis, either intra- (D-cycloserine) or extra-cellularly (vancomycin, oxacillin, bacitracin), at different exposure times and concentrations. The qualitative comparison of differential expression of the cell wall stress stimulon genes in our and previously described studies is presented in Table 2. Despite the different experimental conditions, the cell wall stress stimulon genes react in a similar manner, independently of the bacterial strain and incubation time. Moreover, in our experiment, the transcriptional response of these genes is seen to be time and concentration dependent (Table 2). Their expression is controlled mainly by the vraSR two component system and it has been shown that the VraSR regulon is induced specifically only by cell-wall-active antibiotics [10]. Fosfomycin strongly induced the vraS (Table 2) and vraR (Additional file 1) genes and many of the genes they regulate - not only cell wall synthesis genes but also those for chaperones, heat shock proteins and osmoprotectant transporters. The rib and ure operons, involved in cofactor 


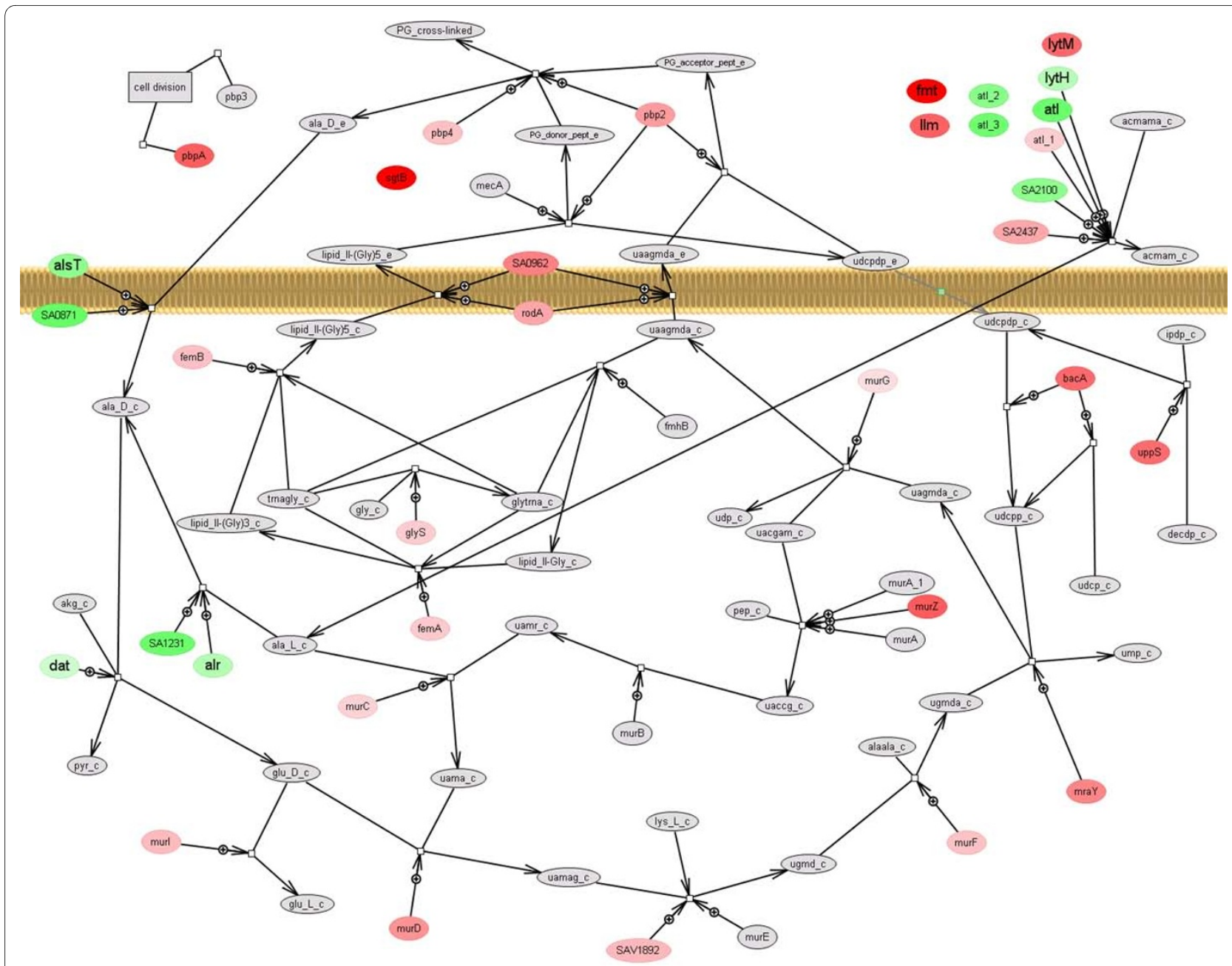

Figure 5 Visualization of S. aureus peptidoglycan metabolic pathway. Node colours correspond to fold changes of differentially expressed genes $40 \mathrm{~min}$ after treatment with $4 \mathrm{\mu g} / \mathrm{ml}$ of fosfomycin (red - upregulated, green - downregulated, grey - genes not differentially expressed). Metabolites are represented by grey-shaded nodes without the plus sign on the connecting arcs.

biosynthesis and urea degradation and, which were induced by some cell-wall-active antibiotics, were also induced at the latest time point in our experiment.

\section{A transcriptional response specific to MurA inhibition}

We performed a meta-analysis to identify groups of genes responding differently to fosfomycin and to other antibiotic treatments. For example, the transcriptional response to ciprofloxacin [11], an inhibitor of bacterial DNA gyrase, is clearly different from that of fosfomycin, because the cell wall stress stimulon genes were not activated. Similarly, the transcriptional profile of the antiseptic compound triclosan, that targets fatty acid biosynthesis [12], confirms the specificity of the cell wall stress response. The effects of fosfomycin on S. aureus metabolism, supported by our transcription data, are schematized in Figure 6. The inhibition of MurA causes accumulation of its substrate phosphoenolpyruvate (PEP) which is known to act as a carbon starvation signal. PEP accumulation was shown to be responsible for downregulation of several central metabolism genes and nucleic acid biosynthesis genes in different organisms including bacteria [13]. A downregulation of pur and pyr operons was observed at the latest time point. Downregulation of both operons has also been reported in the SOS response [8], acid-shock response [7], ciprofloxacin response [11] and in the S. aureus MurF underexpression mutant [6].

In order to reach target enzymes MurA and MurZ, fosfomycin has to cross the cell membrane. Because of its hydrophilic nature it uses the active transport systems (ABC transport proteins), specifically the L- $\alpha$-glycerophosphate and the glucose-6-phosphate uptake systems [1]. The PEP phosphotransferase system (PTS) mediates the uptake and phosphorylation of carbohydrates and 
Table 2: Expression of "cell wall stress stimulon" genes: comparison of current study with published results in the SAMMD.

\begin{tabular}{|c|c|c|c|c|c|c|c|c|c|c|}
\hline \multirow[t]{2}{*}{ N315 LOCUSa } & \multirow{2}{*}{$\begin{array}{c}\text { Gene } \\
\text { Nameb }\end{array}$} & \multicolumn{7}{|c|}{ Expression fold changec } & \multirow[t]{2}{*}{ Gene Product Descriptione } & \multirow{2}{*}{$\begin{array}{l}\text { TIGR } \\
\text { Functional } \\
\text { Group }\end{array}$} \\
\hline & & t10c1 & t20c1 & t40c1 & t10c4 & t20c4 & t40c4 & $\begin{array}{l}\text { Cell wall } \\
\text { active } \\
\text { antibioticsd }\end{array}$ & & \\
\hline SA0909 & fmt & & & 2.65 & & 1.83 & 3.23 & + & $\begin{array}{l}\text { Fmt, autolysis and methicillin resistant-related } \\
\text { protein }\end{array}$ & Cell envelope \\
\hline SA1549 & & & & 1.38 & & 0.63 & 1.87 & + & hypothetical protein, similar to serine proteinase & Protein fate \\
\hline SA1659 & prsA & & & 1.57 & & 0.94 & 1.89 & + & peptidyl-prolyl cis/trans isomerase homolog & Protein fate \\
\hline SA1691 & sgtB & & 0.37 & 2.37 & & 1.31 & 3.14 & + & $\begin{array}{l}\text { hypothetical protein, similar to penicillin-binding } \\
\text { protein } 1 \mathrm{~A} / 1 \mathrm{~B}\end{array}$ & Cell envelope \\
\hline SA1701 & vraS & & 0.28 & 2.05 & & 1.21 & 2.93 & + & two-component sensor histidine kinase & $\begin{array}{l}\text { Cellular } \\
\text { processes }\end{array}$ \\
\hline SA1702 & & & & 2.25 & & 1.29 & 3.34 & + & conserved hypothetical protein & Unclassified \\
\hline SA1703 & & & & 2.63 & & 1.47 & 3.54 & + & hypothetical protein & Unclassified \\
\hline SA1712 & & & & 0.69 & & 0.41 & 1.60 & + & conserved hypothetical protein & Unclassified \\
\hline SA1926 & murZ & & & 0.94 & & 0.51 & 1.45 & + & $\begin{array}{l}\text { UDP-N-acetylglucosamine 1-carboxylvinyl } \\
\text { transferase } 2\end{array}$ & Cell envelope \\
\hline SA2103 & & & & 1.58 & & 0.87 & 2.11 & + & $\begin{array}{l}\text { hypothetical protein, similar to lyt divergon } \\
\text { expression }\end{array}$ & $\begin{array}{l}\text { Regulatory } \\
\text { functions }\end{array}$ \\
\hline SA2146 & tcaA & & 0.27 & 2.07 & & 1.27 & 2.69 & + & TcaA protein & $\begin{array}{l}\text { Energy } \\
\text { metabolism }\end{array}$ \\
\hline SA2220 & & & & 0.95 & & 0.47 & 1.48 & + & hypothetical protein & $\begin{array}{l}\text { Energy } \\
\text { metabolism }\end{array}$ \\
\hline SA2221 & & & & 1.92 & & 0.96 & 2.59 & + & hypothetical protein & Unclassified \\
\hline SA2297 & & & & & & & 0.37 & + & $\begin{array}{l}\text { hypothetical protein, similar to GTP- } \\
\text { pyrophosphokinase }\end{array}$ & Unclassified \\
\hline SA2343 & & -0.73 & 2.11 & 7.08 & & 5.50 & 7.62 & + & hypothetical protein & Unclassified \\
\hline SA0423 & & & & -0.47 & & & -1.34 & - & $\begin{array}{l}\text { hypothetical protein, similar to autolysin } \\
\text { (N-acetylmuramoyl-L-alanine amidase) }\end{array}$ & Unclassified \\
\hline \multirow[t]{2}{*}{ SA0905 } & atl & & & -0.54 & & & -1.24 & - & autolysin & Cell envelope \\
\hline & & & & -0.51 & & & -1.19 & & & \\
\hline
\end{tabular}

a S. aureus N315 genome ORF locus.

$b$ Previously described gene name.

$c$ Gene expression $\log _{2}$ fold change of treated vs. non-treated bacteria. Abbreviations correspond to experimental design points.

$d$ Previously reported expression increase (+) or decrease (-) of cell-wall-antibiotic treated vs. non-treated bacteria.

e Gene product functional annotation. 


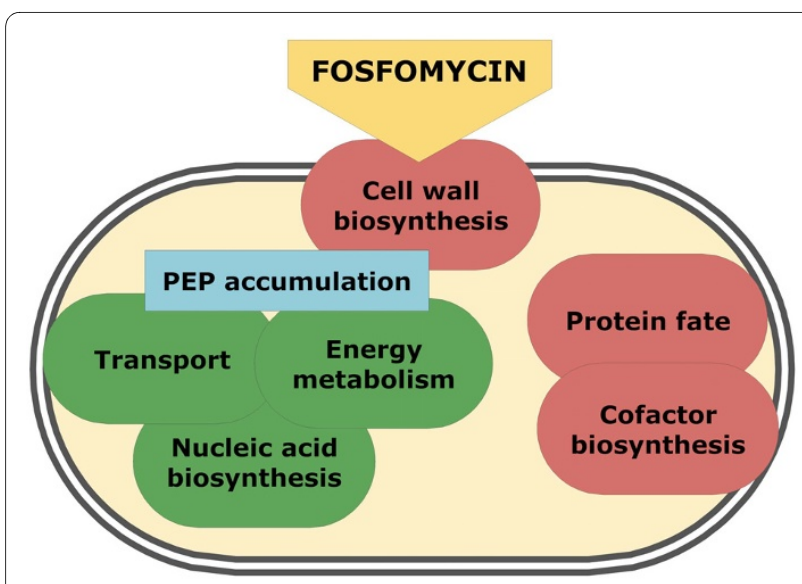

Figure 6 Fosfomycin effects on S. aureus metabolism supported by transcriptional data in this study. Processes in red ovals were induced and those in green ovals were repressed by fosfomycin treatment.

controls metabolism in response to carbohydrate availability, and can therefore affect the whole cell metabolic rate [14]. GSEA shows that PTS was downregulated by fosfomycin 20 and 40 minutes after treatment. This downregulation could be a defense mechanism against the influx of fosfomycin. It has been reported that PTS mutant bacteria are highly resistant to fosfomycin [15] and that some fosfomycin-resistant $E$. coli isolates have altered $g l p T$ and/or $u h p$ transport systems [16]. The downregulation of PTS genes can also contribute to PEP accumulation [13]. As shown in Figure 3 and Table 1, transport processes in general were significantly downregulated. The majority of differentially expressed genes in this group encode proteins that transport oligopeptides (opp genes), amino acids, sugars, polyamines (potA$B C D$ ) and cations into the cell. Genes encoding iron transport and binding proteins, belonging to the Isd system, were also downregulated similarly as in a MurF underexpression mutant study [6]. However, a small proportion of transport genes were upregulated, including some amino acid and oligopeptide carrier genes and the sodium/hydrogen exchanger genes mnhBCDEG.

The energy metabolism group, consisting of genes involved in sugar metabolism, amino acid degradation and TCA cycle, were generally downregulated (Figure 3), consistent with a starvation response. The downregulated amino acid metabolism genes include met and dap operons; additionally, the aspartate family was shown to be significantly downregulated by GSEA (Table 1). Upregulated amino acid metabolism genes include genes involved in cysteine biosynthesis and synthesis of cystathionine. Various tRNA synthetases, probably connected to amino acid biosynthesis, were also downregulated.

Strong downregulation of virulence genes by fosfomycin was observed, especially $40 \mathrm{~min}$ after treatment.
These genes include hla, spa, aur, sspABC and 16 cap genes (capA - capF) encoding capsular polysaccharide synthesis enzymes. Capsular genes were also downregulated in the SOS response [8], but upregulated by cycloserine treatment [9], sigB mutant [17] and biofilm forming S. aureus [18]. It has been shown that cap genes and various virulence factors are regulated by Sae and Agr global regulatory proteins. It was shown that Agr causes induction, and Sae repression, of cap genes [19,20], but in our experiments none of these regulatory genes were differentially expressed.

\section{Conclusions}

A pathway-based approach enabled us to determine that the response of $S$. aureus to fosfomycin is not only time but also concentration dependent, and that the major transcriptional switch occurred after 20 to $40 \mathrm{~min}$ of treatment. The fosfomycin response was similar to those of other cell-wall-active antibiotics in the cell envelope pathway and the cell wall stress stimulon genes. However, in contrast to previously described cell-wall-active antibiotic treatments, we have identified several pathways and genes downregulated by fosfomycin, such as transport, nucleic acid biosynthesis, energy metabolism and virulence genes. The downregulation of these pathways was explained by a starvation response induced by PEP accumulation. We have shown that transcriptomic profiling, in combination with meta-analysis, is a valuable tool in determining bacterial response to a specific antibiotic.

\section{Methods}

\section{Bacterial growth conditions}

Staphylococcus aureus, strain ATCC 29213 was cultured in a small volume of cation-adjusted Mueller-Hinton broth medium (Sigma-Aldrich) and grown in Erlenmeyer flask on a gyratory shaker $(200 \mathrm{rpm})$ at $37^{\circ} \mathrm{C}$. The overnight culture was diluted 100 -fold in $300 \mathrm{ml}$ of medium and grown under the same conditions in 1-L Erlenmeyer flasks until $\mathrm{OD}_{600}$ reached 0.3, which corresponded to the early exponential stage of growth.

\section{Antibiotic treatment}

With the potential of testing new chemical entities in mind, the experiment was designed to allow substances slightly soluble in water to be tested. Fosfomycin (Sigma) was diluted in DMSO (Sigma) to give final concentrations of $5 \%$ DMSO with 1 (c1) and 4 (c4) $\mu \mathrm{g} / \mathrm{ml}$ of fosfomycin. DMSO alone was added to the control cultures (c0), to normalize the effects of DMSO treatment.

Appropriate fosfomycin concentrations were determined in a preliminary growth study (data not shown). Growth rate (measured as OD) and proportion of live cells determined with the LIVE/DEAD BacLight ${ }^{\mathrm{mw}}$ Bacterial Viability Kit (Invitrogen) were monitored for a range 
of concentrations from 1 to $1024 \mu \mathrm{g} / \mathrm{ml}$. For the microarray experiments concentrations were selected that did not affect bacterial growth in the first few hours after treatment. The experiment was repeated four times, from four independently grown bacterial inoculates, thus yielding 40 samples.

\section{Sampling and RNA preparation}

The bacterial culture (prepared as described above) was divided into 10 flasks ( $19 \mathrm{ml}$ per flask) containing previously prepared fosfomycin solutions. Cultures were grown as described above and sampled ( $7 \mathrm{ml}$ per flask) at the time of treatment $(\mathrm{t} 0)$ and $10(\mathrm{t} 10), 20(\mathrm{t} 20)$ and 40 minutes (t40) after treatment. The OD of each culture was measured immediately before sampling (data not shown) and the cultures were stabilized using RNAprotect Bacteria Reagent (Qiagen), following the manufacturers protocol. The bacterial pellets were stored at $80^{\circ} \mathrm{C}$.

RNA was isolated from bacterial pellets by enzymatic cell wall lysis [21] followed by RNeasy Mini Kit (Qiagen) purification. Two hundred $\mu \mathrm{l}$ of lysis buffer (20 mM TRIS $\mathrm{HCl}, 50 \mathrm{mM}$ EDTA, $200 \mathrm{~g} / \mathrm{l}$ sucrose, $\mathrm{pH}$ 7.0), containing lysostaphin (Sigma; $15 \mu \mathrm{g} / \mu \mathrm{L}$ ) was added to the cell pellet and incubated on ice for 20 minutes. The lysate was transferred to a water bath at $37^{\circ} \mathrm{C}$ for 3 minutes. After incubation, $200 \mu \mathrm{l}$ of $2 \%$ SDS and $7 \mu \mathrm{l}$ of proteinase K were added and the lysate incubated at room temperature for 15 minutes. $800 \mu \mathrm{l}$ of the RLT buffer (from RNeasy Kit) was added to the lysate, vortexed vigorously and sonicated for 5 minutes at $56^{\circ} \mathrm{C}$. After the addition of $600 \mu \mathrm{l}$ of absolute ethanol, the lysate was transferred to the RNeasy Mini columns and centrifuged until all the lysate was used. The remaining steps were as described in RNeasy Mini Kit manufacturer's protocol. The elution was performed twice with pre-heated $\left(60^{\circ} \mathrm{C}\right)$ water and 5 minutes incubation time. To remove remaining genomic DNA, total RNA samples were treated with DNase I (Deoxyribonuclease I, amplification grade, Invitrogen), as recommended by manufacturer, only with lower optimized DNase concentration of $0.25 \mathrm{U}$ per $\mu \mathrm{g}$ of total RNA. The RNA was purified and concentrated using RNeasy Min Elute Kit (Qiagen). Finally the RNA was checked for quality and quantity using absorbance measurements (Nanodrop) and agarose gel electrophoresis (data not shown). Two samples did not meet the quality demands and were not used for microarray hybridization.

\section{Microarray hybridization}

RNA was labelled and hybridized to GeneChip ${ }^{\circ}$. aureus Genome Arrays (Affymetrix) according to the GeneChip Expression Analysis Technical Manual, the section for prokaryotic antisense arrays. Targets were prepared by cDNA synthesis with random primers, RNA degradation,
cDNA purification and fragmentation, followed by terminal labelling with biotin. Labelled cDNA was hybridized on the microarrays, which were subsequently washed, stained and scanned.

\section{Quality control and statistical data analysis}

Data was analysed with bioconductor ( $\mathrm{R}$ version 2.10.0; http://www.bioconductor.org) packages affy [22], gcrma [23] and limma [24]. Quality control of the microarray consisted of visual inspection of various diagnostic plots, namely boxplots of transcript intensities, image plots of arrays and MA plots of raw data. Additionally, parameters from the Affymetrix software were evaluated. Moreover, RLE (Relative Log Expression) and NUSE (Normalized Unscaled Standard Error) plots were constructed [25]. Of 38 analyzed arrays, one did not meet the quality requirements and was therefore excluded from further analysis.

Data pre-processing and expression value calculation were carried out using two procedures, yielding 2 separate datasets. In the first, a combination of rma convolution method for background adjustment [26], invariantset for normalization [27], pm correction as from the mas manual, and liwong method summarization $[27,28]$ were applied. In the second procedure, all the preprocessing steps were performed simultaneously using gcrma [23].

In order to find differentially expressed genes a statistical model was formulated $(\mathrm{p}<0.05)$ to compare gene expression in bacteria exposed to fosfomycin concentrations $\mathrm{c} 1$ and $\mathrm{c} 4$ with that of the control (c0) at a given time point. To decrease false discovery rate, the results coming from different pre-processing procedures were combined and only the intersection of genes, differentially expressed following both procedures were taken into account for the biological interpretation of the results [29].

\section{Pathway analysis}

Biochemical reactions from $S$. aureus metabolic network reconstruction iSB619 [4] were obtained from BIGG database http://bigg.ucsd.edu/ and coupled with TIGR $S$. aureus annotation [30] downloaded from TIGR CMR database http://cmr.tigr.org/tigr-scripts/CMR/ CmrHomePage.cgi. Pathway database and expression profiles for all experimental time points were imported to Pathway Studio software (version 4.0; Ariadne Genomics Inc). Differentially expressed genes were queried for presence in metabolic network. Pathways constructed in Pathway Studio were examined and interpreted manually. Pathway Studio .gpc file is available as Additional file 2.

Gene set enrichment analysis (GSEA) [31] was applied to search for groups of genes involved in the same processes (gene sets) that were altered significantly by fosfo- 
mycin treatment. Individual GSEA was performed for a data set including control and both fosfomycin treatment concentrations (1 and $4 \mu \mathrm{g} / \mathrm{ml})$ for the selected time point. Gcrma-normalized data was filtered for signal intensity greater than 10 . The signal intensities from the same time point were overlapped on 40 gene sets (see Additional file 3) based on TIGR S. aureus annotation [30] and measured for the enrichment of genes at the top or bottom of the gene list to determine their correlation with the logarithm of fosfomycin concentration (gene set's phenotype). The GSEA parameters used included: Pearson metric and gene set size restrictions, 10 minimum, 500 maximum. Gene sets significantly modified by fosfomycin treatment were identified using a multiple hypothesis testing FDR $<0.25$. GSEA was performed for each time point (10, 20 and $40 \mathrm{~min}$ ) at which gene expression was correlated with fosfomycin concentration. Positive correlation was interpreted as up-regulation of a gene set resulting from drug treatment; a negative correlation was interpreted as down-regulation.

\section{Meta-analysis: integration of gene expression data from other sources}

Our experimental data was compared to other publicly available $S$. aureus transcriptomic data. To ease the comparison, the recently published "Staphylococcus aureus microarray meta-database" (SAMMD) was used [3]. The qualitative transcriptional profiles (up or downregulation) were coupled with the quantitative transcriptional profile of fosfomycin to a single spreadsheet (Additional file 1) in order to analyze the similarities and differences between different responses.

\section{Quantitative real-time PCR (qPCR)}

The purified RNA samples from experimental points t40c0, t40c1 and t40c4 were reverse transcribed using High Capacity cDNA Reverse Transcription Kit (Applied Biosystems). The acquired cDNA was used to validate the microarray differential expression for genes listed in Table 3. All qPCR reactions were performed on a LightCycler LC480 Detection System (Roche) in 384-well plate format using universal cycling conditions $\left(2 \mathrm{~min}\right.$ at $50^{\circ} \mathrm{C}$, $10 \mathrm{~min}$ at $95^{\circ} \mathrm{C}$, followed by 50 cycles of $15 \mathrm{~s}$ at $95^{\circ} \mathrm{C}$ and 1 min at $60^{\circ} \mathrm{C}$ ). Real-time PCR was performed in a final reaction volume of $5 \mu \mathrm{L}$ containing $2 \mu \mathrm{L}$ of diluted cDNA sample, $1 \times$ primer-probe mix (TaqMan ${ }^{\circ}$ Gene Expression Assay, Applied Biosystems) and 1× TaqMan Universal PCR Master Mix (Applied Biosystems). Each sample cDNA was tested for five target genes: atl, murZ, oppB, ribB, sgt $B$ and the endogenous control 16S rRNA [32]. The TaqMan chemistry based primers and probes were designed and synthesized by Applied Biosystems (Table 3 ). Each reaction was performed in two replicate wells in two dilutions on the same 384-well plate. An automated liquid handling system (Multiprobe II plus ex, PerkinElmer) was used to prepare cDNA dilutions, to pipette cDNA samples and master mixes onto the 384-well plates.

Data were analyzed using the LightCycler 480 1.5.0.39 Software. The 2nd derivate method was used for all amplicons to determine $\mathrm{Cp}$ values. The standard curve method was used for relative gene expression quantification, and the transcript accumulation of each gene was normalized to $16 \mathrm{~S}$ rRNA. The amplification efficiency and linear range of amplification were followed for each amplicon on each plate by analyzing a reference sample pool in four dilution steps of cDNA with two replicate wells per dilution step. Each sample was analyzed in two dilutions and two replicates per dilution step. Only samples where the $\Delta \mathrm{Cp}$ between two dilutions of target gene did not deviate by more than 0.5 from $\Delta \mathrm{Cp}$ of the reference gene were used for relative quantification. The fold changes for each experimental point were calculated as a quotient of average transcript abundances between treated and control samples from three independent biological replicates in each time point.

\section{Microarray dataset accession number}

Microarray data analyzed in this study have been deposited in the Gene Expression Omnibus database with accession number GSE15394.

Table 3: Primer and probe sequences used for qPCR analysis.

\begin{tabular}{clll}
\hline $\begin{array}{c}\text { Gene } \\
\text { Name }\end{array}$ & Forward Primer & Reverse Primer & Probe \\
\hline murZ & TGGTCCTTCATTTGTAACTGATACGATTt & CCCATGCGCTTTAATTCTTCAACAT & CCGGAGCGTTTAAAC \\
$a t l$ & CCCTACTACACCATCAAAACCAACA & TGTGCGACACCATTGTTGC & ACACCGTCGAAACCAT \\
$r i b B$ & CGTGCCATGAGTGGTAACG & GTTCATCTACATGACCGAGGACAAA & ATGTCCACCAAACCTAC \\
sgtB & GAGCTTATTTTCAACGATTAGCGACA & AATITTGACAACTTGTTGTGTAATGGTACTAC & CACCTTGCACATCTC \\
oppB & TTAGGTGTTGCAGCAGCTACT & GTACAGCAAGTACAAAAGATGGTACAGA & CAACCCAAGAATTTG \\
\hline
\end{tabular}




\section{Additional material}

Additional file 1 Summary table for differentially expressed genes Excel spreadsheet file summarizing the transcriptional data from our study and publicly available transcriptional profiling results from SAMMD.

Additional file 2 Pathway Studio metabolic network. File containing the representation of S. aureus metabolic network (gpc format). The file can be viewed by Pathway Studio software http://www.ariadnegenomics.com/ products/pathway-studio/.

Additional file $\mathbf{3}$ Gene sets used for GSEA. Excel spreadsheet file containing gene sets generated from TIGRFAM ontology that were used to run GSEA.

\section{Authors' contributions}

ŠB performed the microarray experiment, participated in study design, data interpretation and helped to draft the manuscript. MP participated in data analysis (GSEA, Pathway Studio visualization), performed the QPCR analysis, interpreted the data, and drafted the manuscript. DK participated in the design of the study, sample preparation and data analysis (GSEA, pathway visualization). AR performed the statistical analysis. ZP participated in study design, data interpretation and drafting the manuscript. KG participated in the design of the study and data interpretation, coordinated the work and helped to draft the manuscript. MR and UU participated in the design of the study and helped to draft the manuscript. All authors read and approved the final manuscript.

\section{Acknowledgements}

The authors would like to acknowledge Dr Ron Peterson (Novartis Institutes for BioMedical Research) for help with microarray hybridizations and Dr Roger Pain for language revision. The work was supported by Slovenian Research Agency (Grant Nos. P4-0165 and Z4-9697), the European Union FP6 Integrated Project EUR-INTAFAR (Project No. LSHM-CT-2004-512138) under the thematic priority Life Sciences, Genomics and Biotechnology for Health and Lek Pharmaceuticals d.d.

\section{Author Details}

1 Department of Biotechnology and Systems Biology, National Institute of Biology, Večna pot 111, Ljubljana, SI-1000, Slovenia, 2Novartis BPO Mengeš, Lek Pharmaceuticals d.d., Kolodvorska 27, Mengeš, SI-1234, Slovenia and 32Department of Biology, Biotechnical Faculty, University of Ljubljana, Jamnikarjeva 101, Ljubljana, SI-1000, Slovenia

Received: 23 December 2009 Accepted: 1 June 2010

Published: 1 June 2010

\section{References}

1. El Zoeiby A, Sanschagrin F, Levesque RC: Structure and function of the Mur enzymes: development of novel inhibitors. Mol Microbiol 2003, 47(1):1-12.

2. Freiberg C, Brotz-Oesterhelt $\mathrm{H}$, Labischinski $\mathrm{H}$ : The impact of transcriptome and proteome analyses on antibiotic drug discovery. Curr Opin Microbiol 2004, 7(5):451-459.

3. Nagarajan V, Elasri MO: SAMMD: Staphylococcus aureus microarray meta-database. BMC Genomics 2007, 8:351.

4. Becker SA, Palsson BO: Genome-scale reconstruction of the metabolic network in Staphylococcus aureus N315: an initial draft to the twodimensional annotation. BMC Microbiol 2005, 5(1):8.

5. Du W, Brown JR, Sylvester DR, Huang J, Chalker AF, So CY, Holmes DJ, Payne DJ, Wallis NG: Two active forms of UDP-N-acetylglucosamine enolpyruvyl transferase in gram-positive bacteria. J Bacterio/ 2000, 182(15):4146-4152.

6. Sobral RG, Jones AE, Des Etages SG, Dougherty TJ, Peitzsch RM, Gaasterland T, Ludovice AM, de Lencastre H, Tomasz A: Extensive and genome-wide changes in the transcription profile of Staphylococcus aureus induced by modulating the transcription of the cell wall synthesis gene murF. Journal of bacteriology 2007, 189(6):2376-2391.

7. Bore E, Langsrud S, Langsrud O, Rode TM, Holck A: Acid-shock responses in Staphylococcus aureus investigated by global gene expression analysis. Microbiology 2007, 153(Pt 7):2289-2303.
8. Anderson KL, Roberts C, Disz T, Vonstein V, Hwang K, Overbeek R, Olson PD, Projan SJ, Dunman PM: Characterization of the Staphylococcus aureus heat shock, cold shock, stringent, and SOS responses and their effects on log-phase mRNA turnover. J Bacteriol 2006, 188(19):6739-6756

9. Utaida S, Dunman PM, Macapagal D, Murphy E, Projan SJ, Singh VK, Jayaswal RK, Wilkinson BJ: Genome-wide transcriptional profiling of the response of Staphylococcus aureus to cell-wall-active antibiotics reveals a cell-wall-stress stimulon. Microbiology (Reading, England) 2003, 149(Pt 10):2719-2732.

10. Kuroda M, Kuroda H, Oshima T, Takeuchi F, Mori H, Hiramatsu K: Twocomponent system VraSR positively modulates the regulation of cellwall biosynthesis pathway in Staphylococcus aureus. Molecular microbiology 2003, 49(3):807-821.

11. Cirz RT, Jones MB, Gingles NA, Minogue TD, Jarrahi B, Peterson SN, Romesberg FE: Complete and SOS-mediated response of Staphylococcus aureus to the antibiotic ciprofloxacin. J Bacterio/ 2007 189(2):531-539.

12. Jang HJ, Chang MW, Toghrol F, Bentley WE: Microarray analysis of toxicogenomic effects of triclosan on Staphylococcus aureus. App Microbiol Biotechnol 2008, 78(4):695-707.

13. Brauer MJ, Yuan J, Bennett BD, Lu W, Kimball E, Botstein D, Rabinowitz JD: Conservation of the metabolomic response to starvation across two divergent microbes. Proceedings of the National Academy of Sciences of the United States of America 2006, 103(51):19302-19307.

14. Deutscher J, Francke C, Postma PW: How phosphotransferase systemrelated protein phosphorylation regulates carbohydrate metabolism in bacteria. Microbiol Mol Biol Rev 2006, 70(4):939-1031

15. Cordaro JC, Melton T, Stratis JP, Atagun M, Gladding C, Hartman PE, Roseman S: Fosfomycin resistance: selection method for internal and extended deletions of the phosphoenolpyruvate:sugar phosphotransferase genes of Salmonella typhimurium. J Bacteriol 1976, 128(3):785-793

16. Horii T, Kimura T, Sato K, Shibayama K, Ohta M: Emergence of fosfomycinresistant isolates of Shiga-like toxin-producing Escherichia coli $\mathrm{O} 26$ Antimicrob Agents Chemother 1999, 43(4):789-793.

17. Bischoff M, Dunman P, Kormanec J, Macapagal D, Murphy E, Mounts W, Berger-Bachi B, Projan S: Microarray-based analysis of the Staphylococcus aureus sigmaB regulon. J Bacterio/ 2004, 186(13):4085-4099.

18. Beenken KE, Dunman PM, MCAleese F, Macapagal D, Murphy E, Projan SJ, Blevins JS, Smeltzer MS: Global gene expression in Staphylococcus aureus biofilms. J Bacteriol 2004, 186(14):4665-4684.

19. Luong T, Sau S, Gomez M, Lee JC, Lee CY: Regulation of Staphylococcus aureus capsular polysaccharide expression by agr and sarA. Infect Immun 2002, 70(2):444-450

20. Steinhuber A, Goerke C, Bayer MG, Doring G, Wolz C: Molecular architecture of the regulatory locus sae of Staphylococcus aureus and its impact on expression of virulence factors. J Bacterio/ 2003 , 185(21):6278-6286.

21. Kornblum JS, Projan SJ, Moghazeh SL, Novick RP: A rapid method to quantitate non-labeled RNA species in bacterial cells. Gene 1988 63(1):75-85

22. Gautier L, Cope L, Bolstad BM, Irizarry RA: affy--analysis of Affymetrix GeneChip data at the probe level. Bioinformatics 2004, 20(3):307-315.

23. Wu C, Irizarry R, Macdonald J, Gentry J: gcrma:Background Adjustment Using Sequence Information. R package version 21002005

24. Smyth GK: limma: Linear Models for Microarray Data. In Bioinformatics and computational biology solutions using R and Bioconductor Volume 2005. Edited by: Gentleman R, Carey V, Dudoit S, Irizarry R, Huber W. London: Springer :397-420

25. Bolstad BM, Collin F, Brettschneider J, Simpson K, Irizarry RA, Speed TP. Quality assessment of Affymetrix GeneChip data. In Bioinformatics and computational biology solutions using $R$ and Bioconductor Volume 2005. Edited by: Gentleman R, Carey V, Dudoit S, Irizarry R, Huber W. New York: Springer :33-47

26. Irizarry RA, Hobbs B, Collin F, Beazer-Barclay YD, Antonellis KJ, Scherf U, Speed TP: Exploration, normalization, and summaries of high density oligonucleotide array probe level data. Biostatistics 2003, 4(2):249-264. 
27. Li C, Hung Wong W: Model-based analysis of oligonucleotide arrays: model validation, design issues and standard error application. Genome Biol 2001, 2(8):research0032.0031-0032.0011.

28. Li C, Wong WH: Model-based analysis of oligonucleotide arrays: expression index computation and outlier detection. Proc Natl Acad Sci USA 2001, 98(1):31-36.

29. Rotter A, Hren M, Baebler S, Blejec A, Gruden K: Finding differentially expressed genes in two-channel DNA microarray datasets: how to increase reliability of data preprocessing. OMICS 2008, 12(3):171-182.

30. Peterson JD, Umayam LA, Dickinson T, Hickey EK, White O: The Comprehensive Microbial Resource. Nucleic Acids Res 2001, 29(1):123-125

31. Subramanian A, Tamayo P, Mootha VK, Mukherjee S, Ebert BL, Gillette MA, Paulovich A, Pomeroy SL, Golub TR, Lander ES, Mesirov JP: Gene set enrichment analysis: a knowledge-based approach for interpreting genome-wide expression profiles. Proc Natl Acad Sci USA 2005, 102(43):15545-15550.

32. McAleese F, Petersen P, Ruzin A, Dunman PM, Murphy E, Projan SJ, Bradford PA: A novel MATE family efflux pump contributes to the reduced susceptibility of laboratory-derived Staphylococcus aureus mutants to tigecycline. Antimicrobial agents and chemotherapy 2005, 49(5):1865-1871.

doi: $10.1186 / 1471-2180-10-159$

Cite this article as: Petek et al., Revealing fosfomycin primary effect on Staphylococcus aureus transcriptome: modulation of cell envelope biosynthesis and phosphoenolpyruvate induced starvation BMC Microbiology 2010, 10:159

Submit your next manuscript to BioMed Central and take full advantage of:

- Convenient online submission

- Thorough peer review

- No space constraints or color figure charges

- Immediate publication on acceptance

- Inclusion in PubMed, CAS, Scopus and Google Scholar

- Research which is freely available for redistribution 